\title{
EM TEMPOS DE GLOBALIZAÇÃO: MEMÓRIA E CULTURA DOS TRABALHADORES BRASILEIROS
}

\author{
Tulio Barbosa ${ }^{1}$ \\ Elias Coimbra da Silva²
}

\begin{abstract}
Resumo: A História Social do tempo presente não pode ser negligenciada, pois entendemos que a compreensão do contemporâneo é importante para refletirmos as transformações que ocorreram nas décadas de 1990 e 2000; uma vez que nestas décadas as mudanças econômicas, políticas, tecnológicas e culturais foram muito significantes e impactaram diretamente o cotidiano dos trabalhadores brasileiros; assim, o presente artigo apresenta reflexões a partir da relação entre cultura, memória e globalização como centralidade para compreender as transformações no mundo dos trabalhadores e como os mesmos compuseram suas memórias nestes tempos de globalização.
\end{abstract}

Palavras-Chave: Trabalhadores Brasileiros; Memória; Cultura; Globalização.

\section{MEMORY AND CULTURE OF BRAZILIAN LABOURERS IN TIMES OF GLOBALIZATION}

Abstract: The Social History of the present time can not be overlooked, because wehave thought that understanding of contemporary is important for us to reflect the changes that occurred in the 1990s and 2000; since in these decades, the economic, political, technological and cultural were very significant and direct impact on the daily life of Brazilian labourers; therefore this article presents reflections from the relationship between culture, memory and globalization as node to understanding the transformations in the world of labourers and how they composed their memories in these times of globalization.

Key-Words: Brazilian Labourers; Memory; Culture; Globalization.

\section{INTRODUÇÃO}

A única coisa que nos diferencia de peixes num aquário é que temos consciência dos limites de nosso mundo.

Mário Quintana, Caderno H.

A relação memória e cultura (não necessariamente neste sentido) é ponto fulcral para a compreensão das transformações que ocorreram nas últimas décadas no conjunto das sociedades que denominamos ocidentais capitalistas. $O$ presente trabalho objetiva introduzir uma discussão epistemológica referente à memória e à cultura, noções essas imbricadas nas reestruturações do capitalismo pelas políticas neoliberais - conceituadas

\footnotetext{
${ }^{1}$ Graduação em Geografia , Mestrado em Geografia, Doutorado em Geografia, Professor Doutor do Instituto de Geografia da Universidade Federal de Uberlândia-Campus Santa Mônica - E-mail: tulio@ig.ufu.br

${ }^{2}$ Graduação em Geografia, Mestre em Geografia pela Universidade Federal da Grande Dourados, Doutorando pelo Programa de PósGraduação em História da Universidade Federal de Uberlândia-Campus Santa Mônica - E-mail: elias_coimbra@yahoo.com.br DOI: 10.7154/RDG.2012.0023.0006
} 
academicamente e popularmente como globalização. Por uma crítica da relação globalização, memória e cultura, o trabalho centra-se em Certeau (2000) a partir da construção da ideia de discurso e como o mesmo é incorporado pelas elites econômicas, sociais e políticas. Assim, o trabalho tem como centralidade a compreensão do que chamamos de Discurso Vivo, pois a partir de Certeau (2000) o discurso não é mera linguagem ou expressão de ideias, trata-se de incorporação cotidiana dos valores direcionados pelo discurso; assim, a adjetivação: vivo significa movimento constante de ação e reação imbricado às condições materiais e existenciais. O presente trabalho abordará aspectos teóricos como alicerces epistemológicos para posteriores discussões no âmbito da ciência da história. Portanto, o objetivo central é dissertar criticamente acerca da composição da memória e da cultura dos trabalhadores brasileiros sob o impacto destes tempos de globalização.

\section{Ser Feliz em Tempos de Globalização?}

Quando Marcel, personagem de "Em Busca do Tempo Perdido" de Marcel Proust (2004), entre dorme e acorda relembra muitas coisas de sua vida. Assim, no primeiro volume (No Caminho de Swann), onde apresenta sua vida sem muito controle, ele descobre-se lançado na temporalidade sem conseguir firmar-se numa direção plausível, direção que o faça compreender-se; em outras palavras: não há história em Marcel (personagem).

É longa a trajetória do personagem, suas lembranças são lançadas sem muito controle, seu medo e seu tédio da vida entrecruzam-se na formação de uma atmosfera transversal na nulidade do sujeito e na falta de controle do mesmo. Esse procedimento narrativo, intitulado Fluxo de Consciência (HEGENBERG, 2007, p.110) caracteriza-se justamente pela gratuidade e caoticidade dos eventos. No último volume de seis (O Tempo Redescoberto) Proust se vê em Marcel e o obriga a compreender a sua vida e a constituição histórica da mesma, resolve sair de seu quarto e viver. Enfim, suas lembranças constituíram-se em memórias e essas passaram a fazer parte de sua vida - não mais como aquilo que foi - agora como o vir a ser, como projeto existencial, como constituição gnosiológica entrelaçada à possibilidade de ser. Marcel e Marcel caminharam, portanto, ontologicamente.

Proust pelas reflexões literárias com Marcel compreendeu sua história e a urgência em construir ininterruptamente sua própria história. Refletiu e resistiu à inoperância de sua 
condição humana, em outros termos: fez-se. Para isso foi necessário compreender a infelicidade em que vivia, infelicidade desdobrada em sua inatividade.

Tais exigências não nos parecem ser diferentes nesses tempos de globalização. Aos trabalhadores restam-Ihes os sonhos, ou melhor, são prometidos alguns sonhos a partir da lógica do consumo e esses norteados por uma felicidade apoiada no que Thompson (2001) conceituou como ética aquisitiva. Tal ética, pautada no consumo, é ampliada cotidianamente pelas exigências da "inevitabilidade" da felicidade alcançada somente por esse trajeto. Tal trajeto tem a globalização como ponto de partida e chegada simultaneamente, ou seja, a construção da ideia de globalização justifica o projeto individual de cada trabalhador: ser multifuncional e polivalente. Assim, a ideologia aponta que: ao conquistar a multifuncionalidade e a polivalência o trabalhador estará apto para buscar a felicidade com maior eficiência, pois tem características importantes para serem aproveitadas pelas empresas e; assim, conseguirá vender melhor sua força de trabalho e, consequentemente, adquirir mais mercadorias e serviços resultando na felicidade aquisitiva. A felicidade deve ser almejada e com ela, os meios para alcançá-la. Trata-se daquilo que conhecemos como Projeto de Vida, que nada mais é do que a aplicação, na esfera individual e mundana, do know-how administrativo-empresarial, ou seja, a racionalidade weberiana levada às últimas consequências.

A partir de Bifo (2003) entendemos que o pensamento globalizante engessou o conceito de felicidade e o que poderia ser usado pelos trabalhadores como arma política, ficou às margens da história. Pois, na medida em que a felicidade deve ser construída e durante tal construção - seja ela ou não conclusa - é que o sujeito é capaz de se reconhecer como humano seja a partir de sua história, ou a partir do produto não alienado de seu trabalho. Assim, a felicidade converteu-se numa "pulsão" para comprar. As lutas em prol das melhores condições de vida, que deveriam se realizar coletivamente foram substituídas pela invocação do individualismo e a busca pela felicidade individual. A felicidade, portanto, foi e é construída como mercadoria. Além disso, a felicidade é - como sugere o texto proustiano - a recompensa individual; o nirvana (onde somente sozinho se pode entrar).

A separação da felicidade coletiva, do bem comum para todos e a comunidade harmônica em todos os sentidos foram com maior ênfase substituída pós-muro de Berlim. O projeto neoliberal construiu discursos apoiados, sobretudo, nos valores individualistas e justificados pela ética capitalista (aquisitiva), discursos esses, em última instância, apoiados no "discurso 
matriz" que propõe que o mundo é natural - o mundo das relações sociais. Aliás, não só natural como ainda, sagrado! Deste modo, é impossível compreender a constituição ontológica do sujeito ocidental sem partir das premissas condicionantes de valores e as recepções destes. Deste modo, a cultura é o movimento dialético pela qual e com a qual recepciona e condiciona os sujeitos, bem como promove e/ou provoca a necessidade de rupturas; todavia, tais rupturas somente ocorrerão se as imposições forem confrontadas.

Todavia, a dificuldade do confronto é explicada pela aludida "naturalidade do capitalismo", e tudo aquilo que se opõe a esse discurso torna-se difícil ou mesmo impossível em ser assimilado e colocado em prática, ou melhor, "não se encaixa".

Para Matos (2009) o capitalismo constrói procedimentos culturais que favorecem a promessa de uma felicidade apoiada no consumo, como se o adquirir fosse a única proposição suficiente para o encontro da felicidade. Por isso asseveramos que o capitalismo promove o sentimento contínuo de frustração e que somente será interrompido pela realização do comprar. Neste sentido, Matos (2009, p. 85) afirma: "Se o homem é um ser desejante, o ser da falta, o capitalismo contemporâneo produz, permanentemente, a falta". Mas falta não é, de fato, suprida pelo consumo. O que ocorre é, nas palavras de Baudrillard (1911), um simulacro. Consumir é obrigatório diante da constituição ética capitalista. Aquele que não consome não agiu eticamente, desta maneira, não é reconhecido socialmente e, então, é rotulado como desajustado (outsider). Matos (2009, p. 85-86) exemplificou assim: "[...] os improdutivos não são mais os ricos, mas o 'pobre parasita'”.

Ser trabalhador, em tempos de globalização, não basta para ser respeitado socialmente e nem para se sentir feliz, precisa-se provar ser apto para o consumo, precisa-se demonstrar materialmente que sua condição econômica vai além de sua condição de classe, como demonstram os estudos de Corbi e Menezes-Filho (2006).

Assim, outro ponto importante é a compreensão da condição de classe pelo fazer-se (THOMPSON, 1987), ou seja, a classe dos trabalhadores não é homogênea e nem alguns trabalhadores se compreendem como tal, desta maneira, os mesmos distanciam-se da compreensão da totalidade concreta e das redes articulares subjetivas de que fazem parte, pois se projetam sempre para além da realidade (de forma individualista). Abdicam, portanto, de um projeto coletivo de crítica ao status quo, projetam-se, para além das delimitações geográficas e históricas, nas quimeras capitalísticas. 
Diante disso, é urgente pensar como a história é escrita/contada para os trabalhadores e sobre os trabalhadores? Como são formadas as memórias destes trabalhadores? E se tais memórias compõem as histórias destes na relação processual pelas e com as articulações escalares, em outras palavras, a história do sujeito (interpretada pelo mesmo) é parte integrante da histórica institucionalizada?

Para compreender o trajeto ontológico do sujeito necessitamos de duas paradas: a memória e a cultura, imbricamento inseparável. Assim, o desafio é entender o sujeito pela condição de classe, como trabalhador, mas sem subtraí-lo da condição humana, sem dogmatizá-lo numa condição classista, já que o trabalhador poderá negar tudo isso. Então, o ponto nodal deste trajeto é o entendimento do sujeito como ser sócio-histórico-geográfico e também como indivíduo. Neste sentido, os trabalhadores lidarão diferentemente com suas memórias a partir da articulação da cultura e, acima de tudo, com seu projeto existencial.

A questão que abre esse trabalho: se é possível ser feliz em tempos de globalização? Deve ser compreendida que a felicidade nestes tempos tem a "face" destes tempos. Portanto, o projeto existencial em busca da felicidade individualizada é a construção teórica e prática de um projeto que subtraí a coletividade. A cultura da felicidade individualizada é consequencia direta destes tempos globalizados.

\section{O Discurso Vivo: Memória e Cultura}

Promover a manutenção do status quo, da "ordem", é algo que, a princípio, pode parecer muito simples - mesmo porque, os mecanismos de socialização vão diluindo-se na solução de continuidade de si mesmos. Mas são inúmeros esforços concentrados para que tal manutenção se torne ideologicamente poderosa.

Por outro lado, os efeitos do processo de manutenção da ordem, muitas vezes se apagam de acordo com o aumento da escala, aumento esse que generaliza a realidade social. Assim, é necessário compreendermos epistemologicamente os elementos contidos no referido processo, a partir dos trabalhadores, portanto pontualmente; via memória e cultura.

Neste trajeto teórico, é obrigatória a compreensão da contemporaneidade, das categorias analíticas enfrentadas pela óptica do presente. Pari passu, devemos compreender o projeto neoliberal na sua materialização, ou melhor, na sua "(re)formação social": a globalização. 0 entendimento das categorias analíticas (memória e cultura), segundo os arautos da 
globalização, foi sinalizado como individuais. Como se não fosse uma questão de sociedade, como se houvesse uma cultura para cada sujeito. Da mesma forma, a memória é atribuída à esfera privada, como se não fosse formada dialeticamente (sujeito-mundo e mundosujeito).

O discurso da globalização simplificou ideologicamente as relações econômicas e políticas, pois transmitia (transmite) a ideia de fim das fronteiras, de fim dos territórios, quando na verdade o rearranjo do capitalismo providenciou o fortalecimento de empresas transnacionais e colocou como refém toda a classe trabalhadora, o que resultou no acirramento da fronteira entre ricos e pobres. Junto disso, a idéia do fim da história afirma a tese de que um outro mundo não é possível.

Ao mesmo tempo em que o capitalismo era rearranjado com as "aberturas modernas dos portos" e justificado com novas práticas de produção e comércio pela subtração das fronteiras dos países periféricos, eram transformadas as culturas nacionais e regionais. Como consequência ocorreram modificações no entendimento dos sujeitos no que tange à relação processual de escalas (geográficas, sociais e históricas) com suas concepções de mundo pelas edificações de suas memórias. As "aberturas dos portos" fortaleceram as empresas transnacionais, pois estavam "livres" para atuarem e lucrarem em todo o mundo, para consumirem até mesmo as almas dos sujeitos. Desta forma, criaram discursos que obrigavam aos trabalhadores comprometerem-se individualmente com suas felicidades.

A retomada do hegelianismo e a prevalência das ideias de Francis Fukuyama a partir de 1989 produziram em escala planetária um novo discurso que desabilitava todo projeto que ousasse contrariar minimamente as premissas da modernidade liberal capitalista. Em outras palavras, a bipolarização do poder, no ocidente", foi substituída por um "novo imperialismo", sem opositores à altura de um conflito; assim, a prevalência e o fortalecimento deste imperialismo foram inevitáveis.

Neste sentido, Harvey (2004) explica que somente foi possível a constituição de um novo imperialismo pela mercantilização da cultura, da história e da criatividade. A mercantilização das ciências significou a subtração da construção crítica tendo seus projetos voltados, sobretudo, para o interesse econômico privado (ou seja, o lucro). Os impactos destes discursos e práticas político-econômicas atingiram diretamente a classe trabalhadora,

\footnotetext{
3 Estamos cientes de que essa denominação tem um significado muito heterodoxo. Nos apoiamos, todavia, guardadas as devidas proporções, no significado que Samuel P. Huntington (1997) empresta ao termo Ocidente; e que inclui a América Latina.
} 
enfraquecendo a organização sindical, exigindo maior qualificação profissional e subtraindo, em muitos países, inúmeros direitos trabalhistas.

Entendemos que tais trabalhadores "moldados" profissionalmente e socialmente no fordismo e sob as políticas sociais e econômicas keynesianas foram atingidos pelo toyotismo e em poucos anos as transformações foram radicais para os trabalhadores, principalmente a edificação de um projeto totalitário de felicidade individual que comprometeu a ampliação do pensamento crítico voltado para a práxis. Compreendemos que tais transformações atingiram diretamente a cultura e a memória destes trabalhadores, bem como a própria história. Diante disso, com Certeau (2000) o direcionamento para o entendimento destas transformações no cotidiano dos trabalhadores passa pela interpretação do que seja real, pois as modificações sociais, políticas e econômicas promoveram rearranjos daquilo que se conhecia e sobre o qual se apoiava, de modo que, a realidade postulada por outros discursos, reafirmou os próprios discursos. O ponto nevrálgico desta constatação certeauniana é a relação entre as modificações históricas e as representações discursivas que são construídas, logo a cultura e a memória são analisadas a partir destes postulados que se tornam verdades. A partir deste ponto os referencias históricos discursivos, quanto à globalização, são vivos, a morte do discurso, como lembrou Certeau (2000), não ocorre aqui, uma vez que a globalização está em processo de formação e transformação.

Vivo o discurso caminha para inevitável morte, como apontou Certeau (2000), pois as prioridades dos referenciais históricos não são permanentes; assim, os trabalhadores são interpretados pelas prioridades referenciais do agora, do que faz sentido agora. O discurso vivo é a prioridade do que e como interpretar a história. Apresentar este discurso academicamente é uma escolha objetiva, pois: “[...] A escolha de um modelo narrativo - ou, mais exatamente, expositivo - é também a escolha de um modo de conhecimento." (REVEL, 1998, p. 37).

Nestes tempos de globalização o discurso vivo está sobrecarregado na esfera econômica. Então, toda justificativa possível para a compreensão da história presente está centrada na economia. Mesmo que alguns pensadores afirmem que essa é uma ideia ultrapassada, ou economicismo (etc), é impossível fugir disso. A economia é o discurso referencial do mundo globalizado. O discurso não é mero discurso, ele se materializa no cotidiano, nas mínimas coisas, nos atos mais simples. A preocupação de Revel (1998) é justamente em compreender 
em escala reduzida o impacto destes discursos, mas não permanecer nesta escala, a articulação escalar é fundamental para a compreensão da totalidade na realidade.

O discurso econômico globalizado é propagado pelos meios de comunicação, pela mídia em geral, pelos livros, pelo ensino, pelas pessoas em todo o mundo ocidental. Avaliar como o discurso é consubstanciado e por quais objetivos o mesmo é difundido, torna-se vital para uma reflexão contemporânea da cultura (como discurso e prática) e da memória (como resiliência ou nulidade). Ainda é necessário compreender como o discurso é propagado por e para as classes socioeconômicas distintas.

Memória e cultura são construções, não são coisas naturais. A memória como lócus do sujeito não promove a individualidade, mas o força a pensar sempre na relação para com o outro. Por outro lado, a memória precisa da cultura para existir e a cultura somente se estabelece pela memória. Neste sentido, pensar os trabalhadores no final do século XX e no século XXI pela memória e cultura é ter em mente de que maneira o discurso vivo econômico apoderou-se do cotidiano dos mesmos.

Assim, a classe socioeconômica não deve ser compreendida como definidora e delimitadora, pois o fazer-se da classe, segundo Thompson (1979), é contínuo numa relação dialética, pois os trabalhadores não são moldados pela sua classe, mas pelas condições materiais e imateriais dos mesmos, somadas às interpretações pessoais que os mesmos tem das suas vidas. Não se trata de privilegiar o sujeito em detrimento da totalidade, mas, sobretudo, como afirmou Revel (1998) apoiado no livro "The making of the english working class" de Thompson, não definir a compreensão por definições pré-construídas. Ao mesmo tempo em que o discurso vivo econômico impõe (ou tenta impor) aos sujeitos um trajeto quase que obrigatório. Enfim, a memória e a cultura dos trabalhadores não são livres, mas também não são perpetuadas em valores e condições subjetivas que sejam impossíveis de serem superadas.

Guattari (2000, p. 158) apresenta a composição da subjetividade, a qual interfere dialeticamente na memória e na cultura:

Toda a história deste fim de milênio nos mostra uma proliferação extraordinária dos componentes subjetivos, tanto para o melhor quanto para o pior. (Subjetividade coletiva de reemergência de arcaísmos religiosos e nacionalistas. Subjetividade maquínica dos mass mídia, da qual se pode esperar que terminará, ela também, por encontrar as vias da singularidade, engajando-se em uma era pós-mídia). Todos esses componentes de subjetividade social, maquínica e estética nos assediam literalmente por toda parte, desmembrando nossos antigos espaços de referência. Com 
maior ou menor felicidade e com uma velocidade de desterritorialização cada vez maior, nossos órgãos sensoriais, nossas funções orgânicas, nossos fantasmas, nossos reflexos etológicos se encontram maquinicamente ligados em um mundo técnico-científico que está realmente engajado em um crescimento louco.

A partir de Harvey (2004) e Sotelo (2003) compreendemos que a aceleração da produção capitalista e o avanço sistemático das tecnologias impuseram aos trabalhadores novos ritmos nos seus cotidianos - o que resulta em novas temporalidades. Tanto no trabalho como fora dele os trabalhadores, nas últimas duas décadas, foram obrigados a viver num turbilhão de problemas: crises econômicas, mudanças na legislação trabalhista, flexibilização dos direitos trabalhistas, maior exigência de qualificação profissional, aumento do uso de máquinas, subtração do número de empregos, diminuição significativa das mobilizações coletivas e "moratória" dos sindicatos. A predominância das políticas econômicas neoliberais e a ditadura da economia de mercado enfraqueceram significativamente as mobilizações dos trabalhadores, pela ameaça constante das demissões em massa, seja pela crise ou pela mobilidade das próprias indústrias. Sequer a difusão da democracia liberal, nos vastos rincões da América Latina, garantiram a presença dos partidos trabalhistas e programas de governo "socialmente responsáveis".

Por isso podermos dizer que, tanto a cultura quanto a memória, serão atingidas por essas transformações no modo de produção, comércio e circulação. Tais transformações redundaram, diretamente, nos objetivos gerais da sociedade ocidental capitalista. Mais do isso! Para além da logística propriamente dita, a qual prima pela utilidade, podemos falar num elogio da utilidade e da eficiência; assim, tudo aquilo que não possa tornar-se útil é desprezado.

Certeau (2000) apresenta o período das Luzes como organizador de uma racionalidade que ainda permanece, uma racionalidade que se volta inicialmente para a compreensão do próprio pensar e, posteriormente, da organização da própria sociedade - que deveria ser organizada pelas bases racionais desenvolvidas por tais pensadores.

A modernidade inaugurada pelas Luzes prossegue com todos seus valores e objetivos até os dias atuais. A globalização, portanto, é resultado deste processo, da racionalização máxima das relações sociais, econômicas e políticas. A globalização se traduz na crença na racionalidade (eficiência) do sistema econômico. Crença apoiada no conhecimento e na utilidade deste para o cotidiano. 
Certeau (2000, p. 177) apontou que no século XIX essa crença no útil já havia sido expressa por Hegel: "O que impõe é o reino do útil. Em breve Hegel caracterizará a verdade da Aufkläurung pela utilidade (Nützlichkeit)." É curioso lembrarmos que, desde a civilização helênica - talvez o mais alto pilar dentre os que sustentam nossa civilização contemporânea - até, aproximadamente, o séc. XIX, a verdade, a beleza e a bondade, que se identificavam, constituíam no objetivo último de grande parte das filosofias (AERTSEN, 2006).

O reino do útil foi criado. A relação memória e cultura desde a llustração carregam o peso inexorável da racionalidade e da utilidade, conceitos formadores de um discurso e de uma nova realidade. Mas, não se trata do caminho diretivo conceito-mundo, o movimento conceito-mundo é dialético e um reforça as condições e imposições do outro.

O discurso vivo da globalização é assimilado pelos trabalhadores, os quais, "desavisadamente", o consideram válido e suas intenções serão guiadas em concordância com o esse mesmo discurso. Assim, toda palavra e toda ação que fere a ordem (o sentido) estabelecida pelo discurso é considerado errôneo, ou mesmo desvirtuado.

\section{A resposta dos trabalhadores}

Na primeira parte deste trabalho a questão inaugural é se existe felicidade nos tempos de globalização. Dentro do reino da utilidade, a felicidade será alcançada mediante o cumprimento do que Thompson (2001) conceituou como ética aquisitiva. Entretanto, como asseveramos, a aquisitividade é uma simulação e, assim, ser feliz é parecer feliz, ou seja, adquirir mercadorias; e é premente que as pessoas aprendam essa lição.

A utilidade, forjada pelo modernismo e reforçada pelas políticas e práticas neoliberais, é uma ideia constante nas considerações dos trabalhadores. O útil liga-se ao poder de consumo, que é outro nome para "valor de troca". Assim, tudo que não produz lucros é inútil para a sociedade ocidental capitalista; e por isso, deve ser excluído. Tais apontamentos condenam os trabalhadores a valorarem elementos da cultura que sejam úteis para seu cotidiano de trabalhador, ao mesmo tempo em que compõe sua memória a partir da seleção utilitária. Não se pode generalizar a memória e a cultura, mas esses elementos compõem o cotidiano no mundo ocidental capitalista e os pesquisadores não devem fechar os olhos para as evidências capturadas na mídia, nas ruas, nas relações pessoais, no cotidiano e outros. 
Diante disso, para pensar a memória e a cultura a partir dos trabalhadores torna-se inevitável a busca pela gênese do que é o trabalhador para o discurso vivo. Historicamente, a ideia de trabalhador é permanentemente construída e reconstruída. Em diferentes períodos históricos as concepções de trabalho e trabalhador são distintas. A ideia de trabalho e trabalhador também tem suas diferenças a partir das condições geográficas, por isso, o presente estudo centra suas preocupações nos trabalhadores brasileiros no território nacional. Para isso é importante apresentar os componentes necessários para a compreensão da memória e da cultura dos trabalhadores.

A composição da memória não é definitiva, a memória é contínua, é desenvolvida ininterruptamente, sendo que esse mesmo desenvolvimento é também afetado pelo "estado da arte" anterior (passado). A memória é a memória de um sujeito, pois o mesmo compreende sua condição humana por aquilo que pensa e esse pensar remonta, continuamente, à memória. A memória liga-se, inseparavelmente, às experiências dos sujeitos, ao mesmo tempo em que as experiências comporão a memória. As lembranças, os sentidos, os sentimentos, os inúmeros aprendizados, tudo isso compõem a memória; assim, em tempos de globalização, a aceleração do conhecimento (mesmo que superficialmente) e as experiências através da mídia (em geral) formulam novas expectativas. A memória é o projeto da ação cotidiana dos sujeitos.

As expectativas atrelam-se ao discurso vivo e as ações (concebendo-as, como motivadas) são consequências desta relação. Nada, porém, é tão simples e tranquilo, pois as contradições, os antagonismos, as diferenças são condições indissociáveis das relações humanas. A memória, portanto, torna-se: memórias. E as memórias são disputadas (entre seus grupos e suas pessoas que são diferentes), luta-se pela hegemonia de "sua" memória, como afirmou Khoury (2004).

Todavia, existe um nexo que unifica as memórias: o discurso vivo. Neste caso, a globalização unifica as experiências. Não desejamos dizer que torna todas as experiências únicas, mas possibilita-as um campo comum (uma moeda de troca). Posto que ninguém possa fugir das condições de classe, das imposições das condições materiais, esse discurso pretende explicar tal condicionamento e, em sua explicação de caráter profundamente ideológico, esse discurso simplifica tudo. 
O discurso simplifica o cotidiano dos sujeitos, já que por ele tudo passa a figurar dentro de uma lógica aparentemente irrefutável. Por exemplo ${ }^{4}$, os trabalhadores na empresa ThyssenKrupp de Santa Luzia e Ibirité, região metropolitana de Belo Horizonte-MG, negaram o apelo do sindicato para a realização de greves contra o não aumento de salários e em oposição às possíveis demissões. Negaram por terem diante deles o perigo iminente do desemprego, pois nos anos de 2008 a 2011 as notícias relacionadas às crises econômicas foram ininterruptas. Assim, nestes anos, as crises (motivadas pela desestabilização do sistema financeiro globalizado) constituíram grande perigo para estes sujeitos que não possuem nada além de sua mão-de-obra (sua força de trabalho) ${ }^{5}$ para ser negociada no mercado capitalista e liberal.

O perigo está gravado nas suas memórias, como um trauma - numa analogia psicanalítica e esse trauma não é uma abstração, mas sim fruto da experiência com o medo, com a insegurança e com a angústia que apenas aqueles que experimentaram o desalento de ser pobre e estar, ao mesmo tempo, desempregado, podem conhecer. Assim, as possíveis ações alternativas (cotidianas) não seriam capazes de produzir qualquer resistência, qualquer enfrentamento, ante o terror do desemprego.

A partir de Williams (1979, p. 91) esse perigo, rememorado, pode ser compreendido como um instante, experimentado, na dinâmica dos pólos dialógicos: limite e pressão.

Em todo um processo social, essas determinações positivas, que podem ser experimentadas individualmente, mas que são sempre atos sociais, na verdade com freqüência formações sociais especificas, têm relações muito complexas com as determinações negativas que são experimentadas como limites. Pois elas não são apenas pressões contra os limites [...] São [...] pressões derivadas da formação e do impulso de um determinado modo social $[\ldots]$

São pressões que emolduram o cotidiano dos sujeitos e mobilizam sua subjetividade para o desenvolvimento de uma memória, memória essa comprometida com o atenuamento das pressões, isto é, assimilação seguida de sua reação proporcional. As experiências cotidianas dos sujeitos deverão ter como objetivo interpretar a pressão como desconfortável e, assim, sua vida cotidiana e sua subjetividade correrão perigo.

\footnotetext{
${ }^{4}$ Informações obtidas pela pesquisa "Globalização e condições de vida dos trabalhadores: um estudo sobre globalização e os trabalhadores da ThyssenKrupp nas cidades de Santa Luzia e Ibirité-MG" sob a coordenação de Paulo Roberto de Almeida e Sérgio Paulo Morais.

${ }^{5}$ Como na definição de Engels: "Por proletariado, [entende-se] a classe dos assalariados modernos que, não tendo meios próprios de produção, são obrigados a vender sua força de trabalho para sobreviver. (Nota de F. Engels à edição inglesa de 1888)." (MARX \& ENGELS, 1998, p.40)
} 
Os trabalhadores da Thyssenkrupp, mencionados anteriormente, preferiram reduzir seus salários e nem cogitaram a ideia de uma greve, pois entenderam que a crise era séria e que seus empregos estavam ameaçados. Entenderam os fatos deste modo, pois a mídia, em geral, veiculou, diariamente, diversas notícias relacionadas à gravidade da crise (ou mesmo crises) econômica, com destaque para as muitas demissões na Europa e Estados Unidos. De fato, esse "conhecimento da crise", junto do temor da mesma, pressionou as ações individuais e coletivas destes trabalhadores para a subtração de seus rendimentos em prol da manutenção de seus empregos. Tais acontecimentos formaram memórias e elas interpretam a crise, sendo, nesse sentido, "memórias da crise". Assim, aos trabalhadores resta-Ihes o conformismo. A questão central é: como essas experiências constituirão as memórias e como esse processo agirá no cotidiano dos trabalhadores?

Para Ginzburg (2009, p. 20) “A memória é uma força ambivalente: pode produzir fidelidade ou obstinação, ódio, cega intolerância. Mas a memória é, como Platão disse sobre a escritura, uma pharmakon: um remédio e, ao mesmo tempo, um veneno".

Trata-se das disputas das memórias, sinalizadas por Almeida e Morais (2011) apoiados em Thompson, isto é, a memória é um lócus de combates onde as armas são os sentidos e os significados, combates que somente são possíveis mediante resistências. Construir memórias combatentes significa edificar lutas futuras, não as submetendo aos ditames de um discurso de ordem.

O discurso vivo preenche os conteúdos de todos os símbolos e ordena sua "gramática". As simbologias são construídas, interpretadas ou reinterpretadas a partir dos elementos discursivos coordenadores de valores e verdades. O discurso promove uma memória institucionalizada e a não concordância com a mesma leva, inevitavelmente, ao conflito. As disputas por "uma" memória são disputas por espaços de ação e pela própria história. A globalização tenta planificar as disputas e diferenças de memórias, já que os objetivos daqueles que coordenam as grandes corporações empresariais e financeiras é a construção de um pensamento único apoiado e justificado pela economia de mercado.

O econômico é o justificável, portanto, a organização social, política, cultural, espacial, territorial, enfim, tudo precisa ser organizado com uma finalidade econômica. Finalidade que pode ser interpretada como a utilidade. Nos tempos de globalização o discurso vivo é a alma da própria globalização (compreendida como um pseudônimo do neoliberalismo). As políticas econômicas e sociais fundamentam-se no livre mercado, na concorrência 
extraterritorial e na regulação do Estado. Apregoa-se que nestes tempos de globalização o Estado sucumbiu diante do mercado, deixando livres as organizações industriais, comerciais e financeiras, isso faz parte do discurso vivo que apresenta a todos o Estado como inoperante e inativo, quando na verdade o Estado opera silenciosamente a favor das grandes corporações capitalistas; e sem o qual tais corporações encontrariam inúmeras dificuldades para operar. O discurso afirma o Estado ausente, na prática o Estado sempre esteve muito presente e a favor de grupos dominantes econômica, política e culturalmente. Em suma, os grupos dominantes definem as ações do Estado e estabelecem uma memória e uma história institucionalizada, como apontou Almeida e Morais (2011, p. 3): "Reconhecemos que tem sido sempre o poder estabelecido que definiu, ao longo do tempo histórico, quais memórias e histórias deveriam ser consideradas para que se pudesse estabelecer uma certa Memória que cunhasse uma História 'certa' ".

É inquestionável a força das classes dominantes. Entretanto, os trabalhadores organizados provaram, historicamente, que detém forças congruentes às da elite. Elaborar suas memórias como resistência é fundamental para a subtração de parte considerável dos engessamentos e inoperatividades em que vivem, cotidianamente, os trabalhadores. Não se trata de construir uma contra-memória, mas possibilitar aos trabalhadores "humanizaremse", ou seja, permitir-Ihes uma elaboração da subjetividade, uma elaboração da memória enquanto sujeitos.

Desta monta, a memória institucional perderá espaço à medida que os sujeitos não se reconhecerem nela e interpretarem seu cotidiano a partir de suas experiências reais em oposição à memória oficial. Exemplificando, os trabalhadores da ThyssenKrupp de Ibirité e Santa Luzia - MG, interpretaram suas ações de deduzir seus próprios salários como algo que beneficiou a todos, a empresa comemorou o acordo e construiu um discurso elaborador de uma memória: os trabalhadores ajudaram uns aos outros e até mesmo a empresa. E essa será a memória institucionalizada e esse o sentido dos fatos.

Diante disso, temos uma questão importante: quando o trabalhador interpretará suas memórias em oposição ao discurso vivo? As memórias dos trabalhadores discordarão da memória institucionalizada a partir de suas experiências cotidianas, pelas e com as quais não tiverem fundamentação no discurso estabelecido. Assim, supostamente, daqui alguns anos, um grupo destes trabalhadores que concordaram em "beneficiar" à empresa e a todos os seus colegas de trabalho com a diminuição dos rendimentos, forem demitidos, o que se 
poderá concluir? Talvez esses trabalhadores demitidos não interpretarão mais seus gestos como justos e suas memórias imbricadas às experiências resultarão numa enorme frustração. Assim, a memória institucionalizada implode no seu confronto com a realidade. Neste sentido, enquanto o discurso é o apaziguador das diferenças e o centralizador do processo de constituição oficial da memória, os trabalhadores continuarão refletindo e vivendo, significantemente, por essa memória.

A memória oficial ou institucionalizada exerce função política e cultural, formata condicionantes irrefutáveis, as quais justificam e organizam o cotidiano dos trabalhadores obrigando-os a ceder aos ditames dos arranjos produtivos e comerciais das empresas. A coletividade dos trabalhadores, em sua crença na validade da memória oficial reforça o padrão cultural resultante do discurso vivo. Assim, fluidez, aceleração do tempo, criatividade e avanços tecnológicos são expressões deste momento e interferem cotidianamente na interpretação dos trabalhadores quanto aos seus cotidianos.

A partir de Sarlo (2005) podemos afirmar que o "tempo" está mais acelerado e que produz, nos sujeitos, vazios históricos; sendo que, a memória é fluida e "passageira". Essa fluidez e inconstância resulta do discurso vivo da globalização, de forma que os sujeitos buscam constantemente novos significados; e esses significados são ditados e confirmados pela ética aquisitiva (THOMPSON, 2001). O vazio histórico do sujeito, ou a nulidade de sua memória diante do cotidiano, obriga-o a adquirir símbolos e significados que possam ser compartilhados com os valores do discurso vivo.

"O presente, ameaçado pelo desgaste da aceleração, converte-se, enquanto transcorre, em matéria da memória" (SARLO, 2005, p. 96). A memória, para esta sociedade, é o hoje, o ontem já passou, o que importa na sociedade ocidental capitalista globalizada é o continuum. A cultura do imediato, do acelerado e do inconsequente prevalece. Fazendo um trocadilho com o bordão de que nossa sociedade é a sociedade do espetáculo, diríamos que ela, mais do que isso, a sociedade da "a(present)ação".

Diante disso, a memória e a cultura são pontos centrais nas formulações e nas ações de resistências diante dos ditames de um discurso e de práticas incongruentes com valores que possam remeter à urgência de justiça, de solidariedade e de igualdade. Assim:

O ponto central não é apenas a escolha das variáveis históricas, num mundo em que a modernidade se tornou irrecusável, mas a dosagem de sua combinação, não mais a partir dos imperativos da técnica, que se tornou subordinada à economia, mas a partir dos valores, o que ensejaria uma nova forma de pensar um porvir onde o social deixaria de ser residual 
e à economia seria atribuído um papel histórico subordinado, em benefício do maior número (SANTOS, 1991, p. 86).

Para isso as transformações nas memórias dependem, sobretudo, das transformações na cultura associadas às mudanças no modo de produção, circulação e consumo; organização política, econômica e social. Cultura, portanto, é a expressão sensível de uma época, pois as tradições, os costumes e o cotidiano são apresentados em similitudes e reconhecidos como parte constituinte, segundo Certeau (1995), do funcionamento social. Deste modo, a cultura, em tempos de globalização, tem sua funcionalidade vinculada à utilidade (lucro). Neste sentido, alguns pesquisadores conceituaram a sociedade, pós-muro de Berlim, como sociedade do consumo, sociedade do descartável e muitos outros, demonstrando que a funcionalidade social liga-se à rapidez, à fluidez e ao imediato; assim, é o cotidiano do trabalhador.

Também é importante compreender como essa sociedade tecnificada, informatizada e ultraracionalizada compôs uma cultura centrada no individualismo. Assim, a reflexão retorna àqueles trabalhadores da empresa ThyssenKrupp, os quais concordaram na diminuição de seus rendimentos: na cultura globalizante esses trabalhadores pensaram individualmente ou coletivamente?

As práticas cotidianas dos trabalhadores revelam as suas representações simbólicas em suas dimensões culturais. A cultura globalizada impõe regras, valores e atitudes que são executadas cotidianamente pelos trabalhadores, além do que apresenta hierarquias simbólicas e práticas.

O mundo globalizado trouxe algumas questões novas e reascendeu algumas antigas: a relação da cultura colonizadora com a colonizada, a tradição nacional, o nacionalismo, povo, população, fronteira, território, espaço nacional, espaço transnacional, memória, experiências individuais, experiências de classe, cultura, lutas de classe, classe socioeconômica, indivíduo, coletivismo, enfim, questões que foram e são enfrentadas cotidianamente pelos trabalhadores. Surgem embates extremamente importantes, os quais sistematizam resistências partilhadas pela conscientização da "produção" de suas memórias. Porém, a cultura dominante prevalece e as disputas são direcionadas pelo discurso vivo comprometido com a ética aquisitiva.

Assim, a partir de Thompson (1979) entendemos que existem culturas, umas populares e outras da elite, chamadas de cultura erudita. Assim, a cultura erudita direciona os elementos 
que os diferenciam do popular, numa necessidade de distanciamento do povo, ao mesmo tempo em que "pasteuriza" a cultura popular para comercializá-la (COELHO, 1980). Essa atitude, obviamente, denota a pré-existência e preponderância da ética aquisitiva; que vai se mostrando assim, o valor-chave.

Portanto, o discurso vivo (o qual percorre as culturas) apresenta, nestes tempos de globalização, símbolos (forjados pelas empresas com sede nos países centrais) que diferenciam as elites. Dentre os quais citemos: as casas luxuosas, carros importados (pois os nacionais simbolicamente são inferiores), roupas de marcas internacionais (pois o nacional é sempre desvalorizado) e destaque nas mídias. A cultura elitista, segundo Certeau (1985, p. 245), impõe uma ordem no cotidiano e estabelece uma hierarquia de prioridades: “[...] De certo modo, um meio particular impõe a todos como a lei aquilo que é somente sua lei. Uma classe privilegiada marca assim seu poder na educação e na cultura".

Certeau (1985, p. 208) afirmou ainda que: “[...] Uma produção social é a condição de uma produção cultural". As condições sociais, neste momento histórico e nas configurações geográficas dadas aos trabalhadores brasileiros, proporcionaram a ampliação de um discurso vivo centrado numa ética elitista e seletiva, fundadora de uma cultura comprometida com os valores impositivos do consumo. Assim, a memória e a cultura destes trabalhadores estarão comprometidas com o ato comprar, o qual, por sua vez, pressupõe o ato de vender sua força de trabalho para adquirir o salário. Comprar é a mola propulsora deste discurso e a sedimentação da cultura globalizada. O comprar, a partir da leitura de Certeau (1985), tornase um novo mito e mitos são cultuados.

O comprar liga-se à felicidade, o ter é fruto dessa necessidade da utilidade. A globalização, por meio de empresas transnacionais, construiu um discurso poderoso que obriga cada vez mais os trabalhadores a lutarem contra suas próprias forças para que o nível exigido de consumo seja realizado, pois segundo Teixeira (2002) a globalização:

Este não pretende mais transformar o mundo. Seu interesse é ensinar as pessoas a se adaptar ao existente e aceitar seus valores e representações como evidências inquestionáveis de um mundo que não tem mais futuro. Trata-se, portanto, de um pensamento pragmático, que se agarra à faticidade do mundo existente, para elevá-la à condição única de toda e qualquer práxis humana (p. 69).

O discurso vivo globalizado apresenta aos trabalhadores práticas cotidianas hierarquizadas e obrigatórias, as quais são ditadas, como mencionou Certeau (1985), por uma classe 
privilegiada. Assim, os trabalhadores são aqueles que executam e executarão o planejamento destas práticas. Ao abdicarem de seus ganhos salariais, os trabalhadores da ThyssenKrupp, cumpriram a agenda neoliberal. O cumprimento desta agenda impossibilitou suas demissões, ao terem emprego, tem salários e esses os mantêm na eterna roda do Samsara: trabalhar, dormir, lazer programado e limitado, prestações de automóveis e de casa. Esse conjunto fornece aos trabalhadores elementos que os façam crer na felicidade construída pelo seu trabalho, pura e simplesmente, por suas atitudes enquanto individuo, enquanto fragmento social. O passeio do fim de semana num carro novo, ou o churrasco com cerveja, tornam-se a expressão de sua liberdade; liberdade de se alienar. Como se o Espaço, a História e a Sociedade fossem prisões.

\section{CONSIDERAÇÕES FINAIS}

O presente trabalho objetivou compreender as transformações no mundo dos trabalhadores pela relação entre cultura, memória e globalização, uma vez que os trabalhadores foram enfraquecidos mundialmente enquanto classe organizada pela imposição neoliberal e tais transformações atingiram o cotidiano destes pela composição de seus imaginários e, portanto, de suas memórias que foram direcionados por elementos formadores da cultura material e imaterial; assim, os trabalhadores adaptaram-se (e adaptam-se) individualmente de maneiras diferentes às imposições da exploração capitalista sem, de fato, realizarem uma frente ampla contra o sistema exploratório. A subtração da força coletiva dos trabalhadores demonstrada nas muitas greves e paralisações nas décadas de 1970 e 1980 resultou na fragmentação dos objetivos coletivos da classe trabalhadora, logo a relação memória e cultura foram transformadas via globalização e a coletividade da classe foi fragmentada em indivíduos, porém, é ainda possível o caminho inverso.

Diante disso, entendemos que os trabalhadores em suas próprias memórias e diante das imposições (reacionárias) que são fruto dos processos de socialização (inclusive a educação formal) experimentam, sempre, a repetição. Pois se é verdade que vivemos numa época de grandes transformações, não é menos verdadeiro que as transformações não ocorrem, indistintamente, ao longo de todo o corpo social, mesmo porque o tempo das conjunturas sociais é mais veloz que o tempo das estruturas sociais (BURKE, 1991, p. 90). Assim, em 
certos campos, como na divisão do trabalho e dos ganhos do trabalho, a sociedade está como que paralisada no tempo.

Com isso, os trabalhadores se vêem condenados ao perpétuo labor e aos trabalhos mais penosos, sem que consigam decodificar sua própria realidade, ou melhor, reconhecer a existência dessa pena que Ihes é aplicada no momento em que nasceram e sobrevivem alguns bem e outros miseravelmente. Mas, vivem ancorados num destino certo segundo o qual, aos mesmos trabalhadores, resta venderem-se pedaço por pedaço, cotidianamente, como apontou Marx (1987). Sendo que a compreensão de sua condição de classe, o entendimento da cultura na qual estão inseridos e o entendimento da memória como resistência, fomentará outros cenários possíveis. Ou pelo menos encetarão a dimensão crítica da realidade presente.

Os trabalhadores não estão fora do mundo, como querem alguns teóricos. Na verdade, cônscios ou não de seu importante papel, eles fazem o mundo, ou melhor, produzem o mundo a partir de seu trabalho - como no poema: "Olhou em torno: gamela, banco, enxerga, caldeirão, vidro, parede, janela, casa, cidade, nação! Tudo, tudo o que existia era ele quem o fazia, ele, um humilde operário, um operário que sabia exercer a profissão." ${ }^{6}$ Além disso, eles também têm sua própria história: a história oculta da qual, vez ou outra, enxergamos lampejos - nem sempre em obras como "O Capital", de Marx. Uma história, que, quando expressa, é geralmente mal-contada, pois serve de ferramenta de dominação (tanto quanto a chibata serviu outrora, no período da escravidão).

Da mesma maneira - e com as mesmas armas com - que os trabalhadores são explorados, também existe a possibilidade dos mesmos remontarem às suas vidas e construírem parâmetros de uma nova cultura, uma cultura própria, que não valorize a fluidez dos sujeitos a partir de uma ética restrita ao ato de comprar. Uma cultura onde eles (trabalhadores) sejam muito mais do que meros "recursos humanos", do que meros "fatores de produção". Tal cultura deve espelhar a vida trabalhadora; com tudo que há de complexo nela e que a "mass media", como produto que é da gerência da classe dominante sobre o imaginário da classe dominada, não consegue nem tanger.

Mesmo que a cultura não determine o mundo do trabalho (a infra-estrutura, na terminologia marxista), a relação entre ambos, relação essa dialética, não é nem um pouco desprezível. Os trabalhadores da ThyssenKrupp reproduziram, na decisão de aceitar as

\footnotetext{
6 “Operário em construção”. In: MORAES, V. Antologia poética. São Paulo: Companhia das letras, 2009. P. 312.
} 
condições assimétricas do patronato, a cultura dominante (e de dominação) que aprenderam. Tal cultura é marcado por uma certa simbologia, mas também, sobretudo, por memórias traumáticas. Aquelas memórias da miséria e do desemprego, citadas anteriormente, anunciam que ainda pode advir mais um período de "vacas magras". São fábula de terror, de sofrimento, o que os antepassados contam, pois - alguns sempre repetem o bordão - "a vida é dura". Nisso apostam os modernos senhores de engenho: a classe dos capitalistas, que podem viver sem trabalhar, ou melhor, desfrutar da vida.

Estes tempos de globalização são tempos difíceis para os trabalhadores. Eles são pressionados no sentido de melhores qualificações, mas vivem cotidianos que não correspondem às expectativas do capitalismo; seja em termo de ônus, seja em termo de bônus (esse principalmente). São tempos realmente difíceis, mas não tempos finais, ou seja, as coisas podem (ou não) mudar. A história ainda segue seu fluxo - como na famosa metáfora do rio - pois essa é sua principal (e inamovível) característica.

Ora uma história das dificuldades, mas que pode ser superada pela história da resistência e da oposição; oposição a tudo aquilo que oprime. Assim, se Marx e Engels (1998) estavam certos quando disseram que a história humana é a história das lutas de classe e que, no capitalismo, tal luta é marcada pela exploração do trabalho pelo capital, então superar o status quo e, consequentemente, superar a própria história humana somente será possível com os trabalhadores compreendendo o sentido e retomando o controle de suas histórias e de suas vidas. Ambas constituindo-se trabalho; e não, meramente, capital.

\section{REFERÊNCIAS BIBLIOGRÁFICAS}

AERTSEN, J. A tríade "Verdadeiro-Bom-Belo": O lugar da beleza na Idade Média. In: PACHECO, M. C.; MEIRINHOS, J. F. (org.) Intelecto e Imaginação na Filosofia Medieval. Atas do XI Congresso Internacional de Filosofia Medieval. Brepols: Turnhout, 2006, vol. I, p. 415435.

ALMEIDA, P., MORAIS, S. P. Anotações sobre cultura, memórias e trabalhadores. Uberlândia: INHIS, 2011. (mimeo.).

BAUDRILLARD, J. Simulacros e Simulação. Trad. Maria João Pereira. Lisboa: Relógio Dágua, 1991. 
BIFO, F. B. La fábrica de la infelicidad. Nuevas formas de trabajo y movimiento global. Madrid: Traficantes de Sueños, 2003.

BLOCH, M. Apologia da história ou o ofício de historiador. Rio de Janeiro: Zahar, 2001.

BURKE, P. A Revolução Francesa da historiografia: a Escola dos Annales (1929-1989). Trad. Nilo Odália. São Paulo: Editora UNESP, 1991.

CERTEAU, M. A cultura no plural. Campinas: Papirus, 1995.

CERTEAU, M. A escrita da história. Rio de Janeiro: Forense Universitária, 2000.

COELHO, T. O que é indústria cultural. São Paulo: Brasiliense, 1980.

CORBI, R. B.; MENEZES-FILHO, N. A. Os determinantes empíricos da felicidade no Brasil. Revista de Economia Política, vol. 26, no 4 (104), outubro-dezembro/2006, p. 518-536. Disponível em: http://www.scielo.br/pdf/rep/v26n4/03.pdf.

FUKUYAMA, F. O fim da história e o último homem. Rio de Janeiro: Rocco, 1992

GINZBURG, C. Memória e globalização. Esboços. v. 16, n. 21, 2009. p. 9-21. Disponível em: http://www.periodicos.ufsc.br/index.php/esbocos/article/view/11444

GUATTARI, F. Caosmose: um novo paradigma estético. São Paulo: 34, 2000.

HARVEY, D. Le Nouvel Impérialisme: accumulation par expropriation. Actuel Marx, 2004/1 n 35, p. 71-90. Disponível em: http://www.cairn.info/revue-actuel-marx-2004-1-page-71.htm.

HEGENBERG, L. Resenhas de Leônidas Hegenberg (2004-2006): matemática, filosofia, linguagem, ficção. Flavio E. N. Hegenberg (org.). Rio de Janeiro: E-papers, 2007.

HUNTINGTON, S. P. O choque de civilizações e a recomposição da ordem mundial. Rio de Janeiro: Objetiva, 1997.

KHOURY, Yara Aun. Muitas memórias, outras histórias: cultura e o sujeito na história. In: FENELON, D. R. et al. (Org.). Muitas memórias, outras histórias. São Paulo: Olho D’Água, 2004. 
MATOS, O. Contemporaneidades. São Paulo: Lazuli Editora/Companhia Editora Nacional, 2009.

MARX, K; ENGELS, F. Manifesto comunista. São Paulo: Boitempo, 1998.

MARX, K. Trabalho Assalariado e Capital. São Paulo: Global, 1987.

PROUST, M. No caminho de Swamm. In: PROUST, M. Em busca do tempo perdido.v. 1 Rio de Janeiro: Ediouro, 2004. p. 21-334.

REVEL, J. Microanálise e construção do social. In: REVEL, J. (org.). Jogos de escalas: a experiência da microanálise. Rio de Janeiro: FGV, 1998, p. 15-38.

SARLO, B. Tempo presente. Notas sobre a mudança na cultura. Rio de Janeiro: José Olympio, 2005.

SANTOS, M. Meio técnico-científico e urbanização: tendências e perspectivas. Resgate Revista de Cultura. Campinas: Unicamp, n. 03, 1991. p. 76-86.

SOTELO, A. La reestructuración del mundo del trabajo, superexplotación y nuevos paradigmas de la organización del trabajo. México: Ítaca, 2003.

TEIXEIRA, F. J.S. Globalização, ideologias e lutas de classes. Estudos de Sociologia. Araraquara, vol. 7, no 12, 2002, p. 61-96.

THOMPSON, E. P. A formação da classe operária inglesa: a força dos trabalhadores. Rio de Janeiro: Paz e Terra, 1987, v.3.

THOMPSON, E. P. As peculiaridades dos ingleses e outros artigos. Campinas: Ed. Unicamp, 2001.

THOMPSON, E. P. Tradición, revuelta y consciencia de clase - Estudios sobre la crisis de la sociedad preindustrial. Barcelona: Editora Crítica/Grupo Editorial Grijalbo, 1979.

WILLIAMS, R. Marxismo e literatura. Rio de Janeiro: Zahar, 1979. 